\title{
Indices of body composition, energy and macronutrient intakes in young men and women with different physical activity
}

\author{
Anna Kęska', Małgorzata Sobczak1, Grażyna Lutosławska², Krzysztof Mazurek², Joanna Tkaczyk', \\ Anna Kłos ${ }^{4}$, Jerzy Bertrandt ${ }^{4}$ \\ ${ }^{1}$ Department of BiologyUniversity of Physical Education, Warsaw, Poland \\ ${ }^{2}$ Department of Biochemistry University of Physical Education, Warsaw, Poland \\ ${ }^{3}$ Department of Sports Medicine, University of Physical Education, Warsaw, Poland \\ ${ }^{4}$ Department of Hygiene and Epidemiology, Military Institute of Hygiene and Epidemiology, Warsaw, Poland
}

Kęska A, Sobczak M, Lutosławska G, Mazurek K, Tkaczyk J, Kłos A, J Bertrandt. Indices of body composition, energy and macronutrient intakes in young men and women with different physical activity. J Pre-Clin Clin Res. 2013; 7(1): 36-39.

\begin{abstract}
It has been shown that body mass index (BMI) commonly used in assessing nutritional status provides equivocal results since subjects with normal BMI are often characterized by abnormal body fat and fat free mass. In consequence, it has been suggested that an indices more precise than BMI of body composition should be used for evaluation of nutritional status and risk of malnutrition and/or obesity. This study aimed at evaluation of the relationship between different indices of body composition and dietary macronutrient intakes in young non-active and active adults. A total of 264 students (136 females and 128 males) participated in the study. Physical activity of 131 subjects ( 69 males and 62 females) was more than $7 \mathrm{~h} /$ week and were classified as active. A total of 133 subjects ( 59 males and 74 females) with physical activity less than $3 \mathrm{~h} /$ week were classified as non-active. Weight, height and waist circumference were measured using standard procedures. Body fat (BF) and fat free mass (FFM) were determined using the bioelectrical impedance method and Tanita equipment. Daily energy and macronutrient intakes were evaluated from four 24-hours recalls concerning two week days and weekend and analyzed using the Dieta 5.0. computerized programme. Basal metabolic rate (BMR) was calculated from body fat and fat free mass, and energy intake (EI) to BMR ratio was calculated to identify the under- and over-reporters. There were no differences in BMI between males and females with different physical activity. Both, non-active females and males were characterized by a higher percent of BF compared to those who were non-active. A difference in FFM was observed between active and nonactive females. Waist circumference in active males was lower vs. their sedentary counterparts. There were no differences in energy consumption between active and non-active students. Neither daily energy intake nor diet composition were correlated with indices of body composition. Additionally, it was observed that in both active and non-active females and active males underreporting was more pronounced in subjects with normal body fat. The above data possibly suggest that numerous participants were characterized by a distorted body image.
\end{abstract}

\section{Key words}

body composition, energy intake, macronutrient intakes, physical activity, young adults

\section{INTRODUCTION}

Numerous studies have indicated that body composition is a reliable marker of nutritional status [1]. On the other hand, it has been shown that body mass index (BMI) commonly used in assessing nutrient intake provides equivocal results. It has been shown that subjects with normal BMI are often characterized by abnormal body fat and fat free mass [2]. In consequence, it has been suggested that an indices more precise than BMI of body composition, such as body fat and fat free mass, should be used for evaluation of nutritional status and risk of malnutrition and/or obesity [3].

Measurements of body fat and fat free mass can be made using different methods, such as computed tomography (CT), magnetic resonance (MR), bioelectrical impedance (BIA) or anthropometric measurements [4]. The advantage of the two latter methods is their simplicity, non-invasiveness, and high reliability.

Address for correspondence: Anna Kęska, Marymoncka 34, 00-968 Warszawa, Poland

e-mail: Anna.Keska@awf.edu.pl

Received: 18 March 2013; accepted: 12 June 2013
In addition, it is well documented that despite body fat content, fat distribution seems to be of importance in health status. Particularly dangerous is an excess of subcutaneous upper body fat, which results in metabolic syndrome, including obesity, insulin resistance, hypertension, impaired glucose tolerance, dyslipidemia, and vascular complications [5]. The risk of their development is estimated using the measurement of waist circumference to height ratio (WHtR), the reliability of which is by $4-5 \%$ higher vs. BMI [6].

It should be recognized that body composition expressed as body fat and fat free mass reflects the total energy daily intake as well as the relative contribution of macronutrient i.e. protein, fat and carbohydrate. The most common cause of excessive body fat storage is a too high fat-originated daily energy intake. According to the latest recommendations, the optimal diet composition provides following percentage of energy $-25-30 \%$ from fat, $10-15 \%$ from protein and $55-60 \%$ from carbohydrate [7]. However, there are many studies indicating that these recommendations are exceeded, leading to an overweight or obesity. The problem now concerns many developed countries and takes on epidemic proportions. 
With the exception of bad dietary habits, another common cause of excessive body fat storage is low daily physical activity. According to American and European studies, only $8-10 \%$ of adults implements health recommendations, i.e. eat fruits and vegetables five times a day, limits fat intake to $30 \%$ of the total energy amount, and regularly exercises [8]. Currently, the use is recommended of any type of physical activity for 30-60 minutes at least 3 times a week [9]. Several studies have shown that physical activity helps reduce body fat and increase lean body mass [10]. On the other hand, very low body fat content due to chronic diseases, inadequate energy intake or excessive activity energy expenditure, brings about at least some components of metabolic syndrome, i.e. insulin resistance or diabetes [11].

\section{OBJECTIVE}

The aim of the presented study was evaluation of the relationship between body composition and dietary macronutrient intakes in young non-active and active adults aged 19-25 years.

\section{MATERIALS AND METHOD}

Subjects. Volunteers were recruited on the basis of advertisements in student dormitories and by word-of-mouth. Finally, a total of 264 students living in Warsaw were selected for the study. A total of 131 physical education students engaged in an obligatory physical activity programme for more than $7 \mathrm{~h}$ /week ( 62 females and 69 males) were classified as active. A total of 133 students ( 74 females and 59 males) from another field of studies, whose physical activity was less than $3 \mathrm{~h} /$ week, were classified as non-active. All the subjects were healthy and not taking any medication on a regular basis. Informed consent was obtained from all students before participation in the study. The study protocol was approved by the local Ethics Committee.

\begin{abstract}
Anthropometric measurements and bioelectrical impedance method. Weight, height and waist circumference were measured. Body height was measured to the nearest 0.5 $\mathrm{cm}$ and body weight to the nearest $0.1 \mathrm{~kg}$. Waist circumference was measured with a tape with $1 \mathrm{~mm}$ accuracy, at midway, between the lower rib and the iliac crest. Anthropometric measurements were taken with the students wearing light clothes without shoes. Body composition was determined by the bioelectrical impedance method (BIA) using BC 418 MA equipment (Tanita Co., Japan). Inter- and intra-assay coefficients of variation for body fat measurements did not exceed $2 \%$.
\end{abstract}

Dietary habits. Daily energy and macronutrient intakes were evaluated from four 24-hours recalls concerning two week days and a weekend. A set of pictures of meals and foods were shown to the participants by an experienced interviewer. The household measures of food intake were converted into gram weights. The interviewer assigned codes to the foods reported by the subjects and performed computer analysis using the Dieta 5.0. The computer programme and the Album of Photographs of Food Products and Meals were purchased at the National Food and Nutrition Institute in Warsaw [12].
Basal metabolic rate (BMR) was calculated from body fat and fat free mass using the following formula: $\operatorname{BMR}(\mathrm{kJ})=[26.88 \times$ body fat $(\mathrm{kg})]+[116.76 \times \mathrm{LBM}(\mathrm{kg})]$ [13] and expressed in calories. A comparison of reported energy intake with estimated BMR was used to evaluate the percentage of under- or over-reporting of energy intake. Values of energy intake to BMR ratio (EI/BMR) lower than 1.4 for sedentary and 1.75 for active subjects were used to identify the under-reporters. Values of EI/BMR higher than 2.4 was used to identify over-reporters [7].

Statistics. The results were expressed as the mean \pm SD. Variables distribution was evaluated using the ShapiroWilk test. The differences between groups was calculated using the Mann-Whitney U-test. Relationships between anthropometric and dietary variables were tested using the Spearman test. Comparison of the percent of underreporters between groups was evaluated using the $\chi^{2}$ test. All calculations were performed using Statistica 9.0 (StatSoft, Inc., USA). The level of significance was set at $\mathrm{p}<0.05$.

\section{RESULTS}

Anthropometric characteristics of participants are shown in Table 1 . There were no statistically significant differences in BMI values between males and females with different physical activity. Both, non-active females and males were characterized by higher body fat compared to those who were active $(\mathrm{p}<0.001$ and $\mathrm{p}<0.03$, respectively). On the contrary, the differences in FFM was observed exclusively between active and non-active females $(\mathrm{p}<0.004)$. In contrast, waist circumference in active males was statistically lower vs. their sedentary counterparts $(\mathrm{p}<0.05)$.

Table 1. Anthropometric characteristics of participants (mean \pm SD).

\begin{tabular}{lcccc}
\hline Variable & $\begin{array}{c}\text { Active females } \\
(\mathbf{n}=62)\end{array}$ & $\begin{array}{c}\text { Non-active } \\
\text { females }(\mathbf{n}=\mathbf{7 4})\end{array}$ & $\begin{array}{c}\text { Active males } \\
(\mathbf{n}=6 \mathbf{6 9})\end{array}$ & $\begin{array}{c}\text { Non-active } \\
\text { males }(\mathbf{n}=\mathbf{5 9})\end{array}$ \\
\hline Age (years) & $19.8 \pm 1.1^{\mathrm{a}}$ & $21.6 \pm 1.9$ & $19.7 \pm 0.8^{\mathrm{f}}$ & $22.7 \pm 2.4$ \\
\hline Weight $(\mathrm{kg})$ & $60.0 \pm 7.6$ & $62.2 \pm 14.4$ & $76.1 \pm 7.9$ & $79.4 \pm 12.1$ \\
\hline Height $(\mathrm{cm})$ & $167.4 \pm 5.5^{\mathrm{b}}$ & $164.9 \pm 6.7$ & $180.7 \pm 6.0$ & $180.4 \pm 6.0$ \\
\hline BMl & $21.4 \pm 2.4$ & $22.7 \pm 4.4$ & $23.3 \pm 2.4$ & $24.4 \pm 3.3$ \\
\hline BF (\%) & $22.9 \pm 4.6^{\mathrm{c}}$ & $27.1 \pm 7.6$ & $12.2 \pm 4.2^{\mathrm{g}}$ & $14.5 \pm 5.6$ \\
\hline BF (kg) & $13.9 \pm 4.4^{\mathrm{d}}$ & $17.6 \pm 9.1$ & $9.5 \pm 3.9^{\mathrm{h}}$ & $12.0 \pm 6.2$ \\
\hline FFM (kg) & $46.0 \pm 4.1^{\mathrm{e}}$ & $44.3 \pm 5.8$ & $66.6 \pm 5.8$ & $67.6 \pm 7.5$ \\
\hline Waist (cm) & $71.8 \pm 6.3$ & $73.4 \pm 11.2$ & $81.1 \pm 6.2^{\mathrm{i}}$ & $85.5 \pm 10.0$ \\
\hline WHtR & $42.9 \pm 3.6$ & $44.5 \pm 6.3$ & $44.9 \pm 3.7$ & $47.3 \pm 5.9$
\end{tabular}

$\mathrm{BMI}$ - body mass index; BF - body fat; FFM - fat-free mass; WHtR - waist-height ratio a - significantly different vs. non-active females, $p<0.001 ; b$ - significantly different vs. non-active females, $p<0.008 ; c-$ significantly different vs. non-active females, $p<0.001 ; d-$ significantly different vs. non-active females, $p<0.05$; e - significantly different vs. non-active females, $\mathrm{p}<0.004 ; \mathrm{f}-$ significantly different vs. non-active males, $\mathrm{p}<0.001 ; \mathrm{g}$ - significantly different vs. non-active males, $p<0.03 ; \mathrm{h}-$ significantly different vs. non-active males, $\mathrm{p}<0.03 ; \mathrm{i}$ significantly different vs. non-active males, $\mathrm{p}<0.05$.

There were no significant differences in energy consumption between active and non-active students (Tab. 2). However, marked differences were observed in diet composition; namely, it was found that non-active females consumed significantly less fat $(\mathrm{p}<0.001)$ and non-active males consumed more protein $(\mathrm{p}<0.001)$ than physically active ones. In addition, in females, physical activity had a significant impact on the percentage of energy from proteins, fats and carbohydrates. 
Table 2. Energy and macronutrient daily intakes, calculated BMR and EI to BMR ratio in female and male students (mean \pm SD)

\begin{tabular}{lcccc}
\hline Variable & $\begin{array}{c}\text { Active females } \\
(\mathrm{n}=62)\end{array}$ & $\begin{array}{c}\text { Non-active } \\
\text { females }(\mathrm{n}=74)\end{array}$ & $\begin{array}{c}\text { Active males } \\
(\mathrm{n}=69)\end{array}$ & $\begin{array}{c}\text { Non-active } \\
\text { males }(\mathrm{n}=59)\end{array}$ \\
\hline $\begin{array}{l}\text { Energy } \\
(\mathrm{kcal} / \mathrm{d})\end{array}$ & $1764.6 \pm 519.2$ & $1642.0 \pm 526.1$ & $2813.0 \pm 689.1$ & $2947.3 \pm 736.8$ \\
\hline $\begin{array}{l}\text { Energy } \\
\text { (kcal/kg FFM) }\end{array}$ & $38.3 \pm 12.0$ & $37.2 \pm 11.8$ & $42.4 \pm 10.4$ & $43.8 \pm 10.7$ \\
\hline Protein (g) & $62.6 \pm 17.7$ & $66.9 \pm 23.4$ & $100.6 \pm 27.5^{\mathrm{f}}$ & $114.0 \pm 34.5$ \\
\hline Protein (\% E) & $14.8 \pm 3.0^{\mathrm{a}}$ & $16.8 \pm 3.7$ & $14.7 \pm 2.6$ & $15.6 \pm 2.6$ \\
\hline Fat (g) & $70.6 \pm 24.5^{\mathrm{b}}$ & $55.3 \pm 23.9$ & $116.2 \pm 34.9$ & $116.7 \pm 38.4$ \\
\hline Fat (\% E) & $35.7 \pm 5.4^{\mathrm{c}}$ & $29.4 \pm 6.8$ & $36.4 \pm 5.9$ & $34.8 \pm 6.2$ \\
\hline $\begin{array}{l}\text { Carbohydrate } \\
\text { (g) }\end{array}$ & $227.0 \pm 72.2$ & $227.6 \pm 79.4$ & $360.0 \pm 102.1$ & $362.1 \pm 87.9$ \\
\hline $\begin{array}{l}\text { Carbohydrate } \\
\text { (\% E) }\end{array}$ & $49.4 \pm 6.2^{\mathrm{d}}$ & $52.8 \pm 7.5$ & $49.5 \pm 8.5$ & $47.5 \pm 6.7$ \\
\hline BMR (kcal) & $1374.6 \pm 133.5^{\mathrm{e}}$ & $1349.6 \pm 211.0$ & $1922.1 \pm 171.3$ & $1964.4 \pm 232.7$ \\
\hline El/BMR & $1.28 \pm 0.41$ & $1.23 \pm 0.40$ & $1.47 \pm 0.36$ & $1.51 \pm 0.38$ \\
\hline
\end{tabular}

BMR - basal metabolic rate; EI/BMR - energy intake to basal metabolic rate ration

a - significantly different vs. non-active females, $p<0.001 ; b$ - significantly different vs. non-active females, $p<0.001 ; c-$ significantly different vs. non-active females, $p<0.001 ; d-$ significantly different vs. non-active females, $\mathrm{p}<0.005$; e - significantly different vs. non-active females, $p<0.05 ; f-$ significantly different vs. non-active males, $p<0.001$

In non-active females, significantly more energy was derived from protein $(\mathrm{p}<0.001)$ and carbohydrate $(\mathrm{p}<0.005)$, and significantly less from fat $(\mathrm{p}<0.004)$, as compared to active females.

No significant relationships were noted between body fat, FFM, WC and WHtR and dietary energy and macronutrient intakes in either active or in non-active participants.

Most students, with the exception of non-active males, markedly under-reported daily energy intakes. In addition, it was noted that the percent of under-reporters was significantly higher in active males and active females than in those who were non-active (Tab. 3).

Table 3. Percent of under- and over- reporters in female and male students

\begin{tabular}{lcccc}
\hline Variable & $\begin{array}{c}\text { Active females } \\
(n=62)\end{array}$ & $\begin{array}{c}\text { Non-active } \\
\text { females }(n=74)\end{array}$ & $\begin{array}{c}\text { Active males } \\
(n=69)\end{array}$ & $\begin{array}{c}\text { Non-active } \\
\text { males }(n=59)\end{array}$ \\
\hline Under-reporters & $53(85.5 \%)^{\mathbf{a}}$ & $46(62.0 \%)$ & $56(81.2 \%)^{\mathbf{b}}$ & $20(33.9 \%)$ \\
\hline Over-reporters & - & - & $1(1.4 \%)$ & $1(1.7 \%)$
\end{tabular}

$\mathrm{a}-$ significantly different vs. non-active females, $\mathrm{p}<0.003$; $\mathrm{b}$ - significantly different vs. nonactive males, $\mathrm{p}<0.001$

It was observed that in active females, non-active females and non-active males under-reporting was more common in subjects with normal body fat (Fig.1; Fig.2). On the other hand, in active males the percentage of under-reporters was highest among individuals with low body fat (Fig.2).

\section{DISCUSSION}

Both active and non-active participants in the presented study were characterized by normal values of BMI according to WHO standards $\left(18.5-25 \mathrm{~kg} / \mathrm{m}^{2}\right)$ [14]. Furthermore, taking into account the recommendations for body fat content in young adults (20-30\% for women and $12-20 \%$ for men) [15], it was observed that most of the subjects were lean.

The presented study confirmed other data indicating that active subjects are characterized by lower body fat content

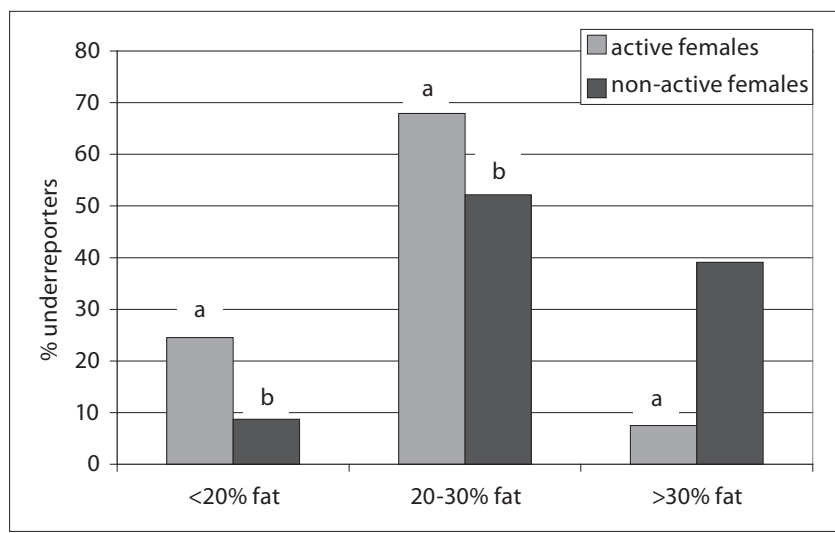

Figure 1. Body fat $(\%)$ in active $(n=53)$ and non-active $(n=46)$ females underreporting their energy intake

a - significantly different vs. active females with low $(<20 \%)$ and high $(>30 \%)$ body fat, $\mathrm{p}<0.001$

$\mathrm{b}$ - significantly different vs. non-active females with low ( $<20 \%)$ body fat, $\mathrm{p}<0.001$

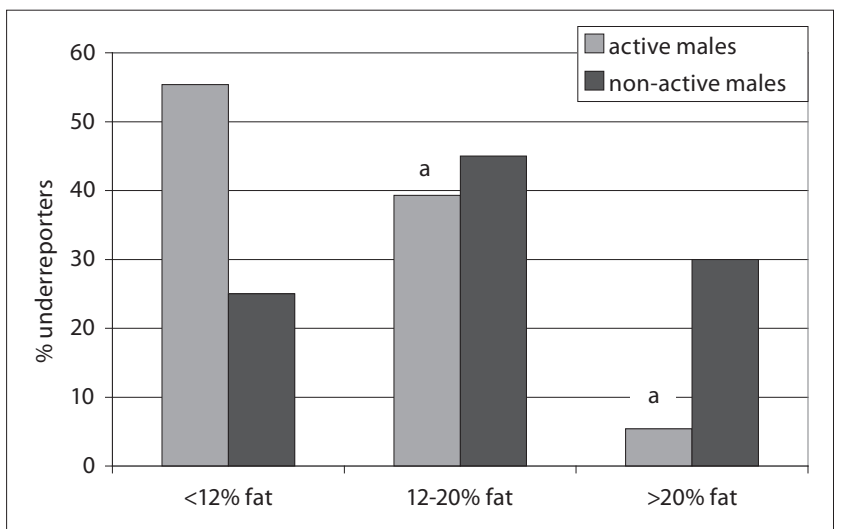

Figure 2. Body fat $(\%)$ in active $(n=56)$ and non-active $(n=20)$ males underreporting their energy intake

a - significantly different vs. active males with high ( $>20 \%)$ body fat, $p<0.001$

than their non-active counterparts, despite the lack of differences in BMI [16]. Additionally, many studies have shown that physical activity also contributes to elevated FFM [10]. However, in the presented study this effect was observed only in females, since FFM was higher in active vs. those who were non-active. This finding is in agreement with the data of Cabrić et al. [17] which indicated that active female students are characterized by the greater FFM and smaller $\mathrm{BF}$ than their non-active counterparts. Moreover, it should be stressed that Guo et al. [18] showed that physical activity has a significant and positive effect on FFM in females, but not in males.

Self-reported energy intake for active and non-active female and male students were similar to those reported by Brevard et al. [19].

It is worth noting that the macronutrient intake in the subjects in the presented study differed significantly from the recommendations, with too high protein and fat and too low carbohydrate intakes [7].

An important finding of the presented study concerns the validity of self-reported daily intakes and high percentage of under-reporters, especially in active males and females and non-active females, which varied from $62.0-85.5 \%$ of all subjects in respective groups. In contrast, the percent of under-reporters in non-active males was lower and equaled $33.9 \%$ of participants. Thus, it could be postulated that in the subjects in the presented study physical activity negatively 
affected the validity of self-reported dietary intakes, which is in agreement of other data [20]. Furthermore, there were no relationships between self-reported daily intakes and objectively measured body composition, further supporting the low reliability of self-reported dietary consumption.

It is noteworthy that a similar percent of under-reporters was demonstrated by Johansson et al. [21] in Norwegian males and females at the end of the $20^{\text {th }}$ century. Thus, it could be postulated that the frequency of under-reporting is relatively stable over many years. This assumption is supported by Rennie et al. [22] who analyzed secular trends in under-reporting in young people in contrast to increasing their body weight. Furthermore, it was indicated that the tendency to under-report is greater in overweight than in normal weight subjects [23].

The influence of body composition on the validity of dietary reporting was also observed in the presented study. In females, despite physical activity, the highest percent of under-reporters was found in subjects with normal (20-30\%) body fat content. In males, the highest percent of underreporters was noted in non-active subjects with lowest body fat content (less than 12\%). These findings probably reflect a distorted body image, at least in some of our subjects. On the other hand, it was demonstrated that with the exception of distorted body perception, other factors, such as sociocultural influence, media pressure, and the constant search for an ideal body, may increase the tendency to under-report daily food intakes [24].

However, it should be pointed out that the relationship between under-reporting and body built in young people is far from being elucidated, since Klingberg et al. [25] found that in 18-20-year-old Swedish males the under-reporters had a higher BMI and body fat than acceptable reporters.

In conclusion, the presented study suggests that young people tend to under-report food consumption. Thus, it is postulate that objective methods for measuring body fat and fat free mass provide more reliable results concerning nutritional status of young people than self-reported dietary intake.

\section{Acknowledgement}

This study was supported by Grants DS.-132 and DS.-147 from the University of Physical Education in Warsaw, Poland.

\section{REFERENCES}

1. Hedley AA, Ogden CL, Johnson CL, et al. Prevalence of overweight and obesity among US children, adolescents and adults, 1999-2002. JAMA 2004; 291: 2847-2850.

2. Kyle UG, Genton L, Pichard C. Body composition: what's new? Curr Opin Clin Nutr Metab Care. 2002; 5(4): 427-433.

3. Kyle UG, Schutz Y, Dupertuis YM, Pichard C. Body composition interpretation. Contributions of the fat-free mass index and the body fat mass index. Nutrition 2003; 19(7-8): 597-604.
4. Ward LC, Dyer JM, Byrne NM, et al. Validation of a three-frequency bioimpedance spectroscopic method for body composition analysis. Nutrition 2007; 23(9): 657-664.

5. Duvnjak L, Duvnjak MJ. The metabolic syndrome - an ongoing story. Physiol Pharmacol. 2009; 60(suppl. 7): 19-24.

6. Ashwell M, Gunn P, Gibson S. Waist-to-height ratio is a better screening tool than waist circumference and BMI for adult cardiometabolic risk factors: systematic review and meta-analysis. Obes Rev. 2012; 13(3): 275-286.

7. Jarosz M, Bułhak-Jachymczyk B. Normy żywienia człowieka. Podstawy prewencji otyłości i chorób niezakaźnych. Wydawnictwo Lekarskie PZWL, 2008.

8. Berrigan D, Dodd K, Troiano RP, et al. Patterns of health behavior in U.S. adults. Prev Med. 2003; 36: 615-623.

9. Haskell WL, Lee I, Pate RR, et al. Physical activity and public health: updated recommendation for adults from the American College of Sports Medicine and the American Heart Association. Circulation 2007; 116: 1081-1093.

10. Kyle UG, Zhang FF, Morabia A, Pichard C. Longitudinal study of body composition changes associated with weight change and physical activity. Nutrition 2006; 22(11-12): 1103-1111.

11. Malina RM, Geithner CA. Body composition of young athletes. Am J Lifestyle Med. 2011; 5: 262-278.

12. Szponar L, Wolnicka K, Rychlik E. Album fotografii produktów i potraw. IŻŻ Warszawa 2000.

13. Garby L, Garrow JS, Jørgensen B, et al. Relation between energy expenditure and body composition in man: specific energy expenditure in vivo of fat and fat-free tissue. Eur J Clin Nutr. 1988; 42(4): 301-305.

14. World Health Organization. Division of Noncommunicable Diseases. Programme of Nutrition Family and Reproductive Health. Obesity: preventing and managing the global epidemic: report of a WHO consultation on obesity. Geneva; 1998. (WHO/NUT/NCD/98.1).

15. Abernathy RP, Black DR. Healthy body weights: an alternative perspective. Am J Clin Nutr. 1996; 63(3 suppl.): 448S-451S.

16. Pescatello LS, VanHeest JL. Physical activity mediates a healthier body weight in the presence of obesity. Br J Sports Med. 2000; 34: 86-93.

17. Cabrić M, Krakowiak H, Janczak R. The relationship between body constitution and body composition in young women. Fiz Pol. 2002; $2(1) ; 1-5$.

18. Guo SS, Zeller C, Chumlea WC, Siervogel RM. Aging, body composition, and lifestyle: the Fels Longitudinal Study. Am J Clin Nutr. 1999; 70; 405.

19. Brevard PB, Ricketts CD. Residence of college students affects dietary intake, physical activity, and serum lipid levels. J Am Diet Assoc. 1998; 96(1): 35-38.

20. Briefel RR, Sempos ChT, McDowell MA, et al. Dietary methods research in the third National Health and Nutrition Examination Survey: underreporting of energy intake. J Am Clin Nutr. 1997; 65 (suppl. 4): 1203S-1209S.

21. Johansson L, Solvoll K, Bjǿrneboe GA, Drevon CA. Under- and overreporting of energy intake related to weight status and lifestyle in a nationwide sample. Am J Clin Nutr. 1998; 68: 266-274.

22. Rennie KL, Jebb SA, Wright A, Coward WA. Secular trends in underreporting in young people. Br J Nutr. 2005; 93(2): 241-247.

23. Vance VA, Woodruff SJ, McCargar LJ, Husted J, Hanning RM. Selfreported dietary energy intake of normal weight, overweight and obese adolescents. Public Health Nutr. 2009; 12(2): 222-227.

24. Costa LC, Vasconcelos FA, Peres KG. Influence of biological, social and psychological factors on abnormal eating attitudes among female university students in Brazil. J Health Popul Nutr. 2010; 28(2): 173-181.

25. Klingberg S, Hallenberg E, Lorentzon M, Mellström D, Ohlsson C, Hulthén L. Characteristics of under- and over-reporters of energy intake among 18-20-year-old males: the Gothenburg Osteoporosis and Obesity Determinants (GOOD) study. Public Health Nutr. 2008; 11(11): $1117-1123$. 